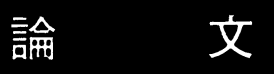

\title{
An Apparatus for Dynamic Birefringence Measurements
}

\author{
Tadashi Inoue, Hirotaka Okamoto, \\ Hiroshi Hayashihara, and Kunihiro Osaki \\ Institute for Chemical Research, Kyoto University, \\ Uji, Kyoto 611, Japan,
}

\begin{abstract}
An apparatus was constructed for simultaneous measurements of the dynamic birefringence and the complex Young's modulus. The frequency range was $1-200 \mathrm{~Hz}$. The instrument was calibrated with a polybutadiene film, for which the stress optical law was expected to hold well. The stress optical coefficient estimated by dynamic birefringence measurement was consistent with the result of the static measurement. The stress-optical law did not hold valid for a polystyrene film containing $5 \mathrm{wt} \%$ dibutyl phtalate in the glass-to-rubber transition region.
\end{abstract}

Key words: Dynamic birefringence / Stress-optical rule / Strain-optical coefficient / Young's modulus

\section{動的複屈折測定装置の製作}

\author{
井上正志・岡本 浩孝・林原広・尾崎 邦宏*
}

（原稿受理：1990年10月15日）

\section{1. 緒言}

高分子物性の研究方法として複屈折の測定は古くから行われ, また測定の対象となった系も幅広い、複折屈の測定は，多くの場 合レオロジー的測定と組み合わせて行われ，高分子の構造，分子 運動などに関する情報を与える，最近では，光学材料としての高 分子の需要が広がり, 光学的性質の精密な制御が要求されるに伴 い，無定形高分子を中心に活発な研究が行われている。

複屈折の測定とレオロジー的測定を組み合わせた研究法は, 流 動光学的方法のひとつであるが，粘弾性測定と同様に変形履歴に より分類することがでさる．定常流を用いた方法は，主に希薄溶 液に使用されている．高分子固体や濃厚溶液には，応力緩和測定 と同様に, 変形後もしくは一定荷重下での複屈折の時間変化を追 跡する方法が用いられ，以下では静的測定法と呼ぶことにする. 振動変形を用いた動的測定法では，複屈折の周波数依存性一動的 複屈折一を測定することができる.

最近の高分子固体に関する研究の多くは，静的測定法で行われ ている．転移領域からガラス状領域では，高分子の力学的性質と 複屈折の温度依存性が異なる場合もあり, 両者の温度依存性を詳 しく調べるためには，一定温度で幅広い時間領域での測定ができ

\footnotetext{
* 京都大学化学研究所 $\overline{\mathrm{T}} 611$ 宇治市五ケ庄
}

る必要がある．静的測定の装置では， 1 ～1,000 秒程度の範囲で は比較的容易に測定することができる，これ以上長時間になると， 複屈折の強度にるよるが，装置の安定性等が問題となる．最近で は, 光弾性素子を用いて入射光を变調させる方法や, 検光子を回 転させる方法などにより, 長時間にわたって, 微小量の複折屈が 精度良く測定できるようになった。 $10^{5}$ 秒程度の測定も行われ， 時間領域にして 5 杕程度の時間領域の情報が得られるようになっ ている.

これまでに動的複屈折が測定された周波数領域は，0.01〜数 $10 \mathrm{~Hz}$ で 3 析程度である. 時間領域の広さでは, 静的測定法が優 れているが, 両者では対象とする時間領域が異なり, 動的複屈折 測定法では静的な測定法より短い $0.01 〜 10$ 秒の時間領域を対象 とする.したがって, 両測定法を組み合わせれば，より広、時間 領域での情報を得ることがでさる，また，動的複屈折測定法では， 緩和スペクトルを求めやすい利点があり, 複屈折の発生機構と分 子運動の関係を分子論的に調べるのに適している.

動的複屈折の測定は，20年ほど前に高分子固体を中心に，精力 的に行われたが，最近ではほとんど行われていないようである。 その頃の測定が，温度依存性を中心にして行われていることから， 測定がかなり煩雑なものであったと推測される．現在では計測技 術も進歩して扣り, 自動化された迅速から精度のよい動的複屈折 
測定装置の製作が可能であろう．この装置をもとに，高分子の複 屈折現象について系統的な研究を行郎ば, 高分子物性に新たな知 見が得られることが期待できる. 本論文では, 動的粘弾性と動的 複屈折が同時に測定できる装置を製作し，無定形高分子の粘弾性 挙動の解明に有効であることを示す。

\section{2. 高分子の複屈折測定の歴史の概略}

粘弾性の測定が希薄溶液から固体までいろいろな系で行われて いるのと同様に，複屈折測定を利用した研究も広い範囲で行われ ている。これらの研究を三つに大別してみると，一つは希薄溶液 について行われた研究で，孤立鎖の動的性質が調ベられた。流動 に上る高分子溶液の複屈折の原因には, 固有複屈折々形態複屈折 がある. 前者はもともと光学的異方性を持つセグメントが流動に よって配向することから生じる，後者は溶媒と屈折率を異にする セグメントが流動によって異方的に分布すること，すなわち高分 子鎖の形が変化することにより生じる．希薄溶液では両者の寄与 があるが，高分子量試料では形態複屈折の方が顕著である．この ような性質に注目して, 定常流の際のセグメントの配向状態など が広く研究された ${ }^{11}$. 動的複屈折測定は, 後に Schrag と共同研 究者によって始められた．複素粘度測定からは高分子鎖内の張力 の配向に関する情報が，動的複屈折の測定からは高分子鎖のボン ド配向に関する情報が得られるから，両者の測定から溶液中の高 分子鎖の動的性質に影響を与える因子，例究ば流体力学的相互作 用，良溶媒効果，高分子鎖の配座や動的な固さなどについて調べ られた2).

光学的異方性を持つ結晶性高分子の研究に, 複屈折測定を利用 することは，極めて自然で有効な手段であり，応力緩和の測定と 同時に複屈折の時間変化の測定が1950年頃すでに行われている ${ }^{3)}$. 1961年には，ポリエチレンの動的複屈折測定が小野木らによって 行われた ${ }^{4)}$. 粘弾性の研究が動的測定が行われるようになって急 速に進んだように，1960年代に数多くの高分子について動的複屈 折測定が行われ，この分野は急に進歩した．また，赤外二色性， 光散乱, X線回折などの他の光学量も測定されるようになり, こ れらは複屈折測定も含め流動光学的方法と呼ばれる. 流動光学に 関するシンポジウムも開かれ，その特集が Journal of Polymer Science, Part C にあるので5)，当時の状況を知ることができる. 流動光学に関する文献は多く，ここでは主なるのを挙げて掠 く ${ }^{6) ~ 9)}$. 無定形高分子の動的複屈折測定も，Read などにより行 われたが ${ }^{10)}$, 流動光学的測定は結晶性高分子, 高分子ブレンド, ブロック共重合体など複雑な組織を持つ系を中心に行われた。

最後に述べるのは, 光弾性則を利用して複屈折測定から応力を 算出する方法で，間接的応力測定法としての複屈折測定の利用法 である.ゴムやガラス状の固体について，応力と屈折率の異方性 成分の間の比例関係, すなわち光弾性則は固体物質の応力分布を 知るために広く応用されているものである．高分子レオロジーの 分野では, 濃厚溶液㧍よび溶融体の定常流について,形態複屈折が 無視できるほど小さいことと光弾性則の成立が明らかにされ，複 屈折測定が力学測定と等価な情報を与えることが示された ${ }^{11), 12)}$. これは時間依存型の流動下でも証明され, 複屈折測定は非定常状 態での法線応力の評価等に応用されている ${ }^{13)}$. 二段階変形のよ5 な複雑な時間依存型の流れでの測定からは, 分子の形態変化に関 する詳細な情報が得られるので，分子運動の理論の検討にも用い

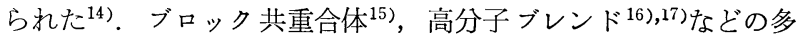
成分系でも，均一一相系では各成分に関して光弾性則が成立する と仮定して，応力への奇与を分離評価することが試みられて拉り， 高分子運動の新しい研究法として注目されている.

\section{3. 動的複屈折測定の原理}

初期長 $l_{0}$ の高分子試料に，周期的な微小変形（振幅 $\Delta l$ ) を加 えると, 試料長 $l(t)$ は,

$$
l(t)=l_{0}+l_{\mathrm{s}}+\Delta l \sin \omega t
$$

となる．ここでは話を一般的にするため，静的な変形 $l_{\mathrm{s}}$ も同時 に印加するものとする，ひずみで畫けば，

$$
\begin{aligned}
\varepsilon(t) & =l_{\mathrm{s}} / l_{0}+\left(\Delta l / l_{0}\right) \sin \omega t \\
& =\varepsilon_{\mathrm{s}}+\varepsilon_{0} \sin \omega t
\end{aligned}
$$

となる。ここで， $\varepsilon_{\mathrm{s}}$ は静的ひずみを， $\varepsilon_{0}$ は振動ひずみを表す. 発生する応力は,

$$
\sigma(t)=\sigma_{\mathrm{s}}(t)+\sigma_{0} \sin (\omega t+\delta)
$$

と表すことができる，以下では，簡単のため $\sigma_{\mathrm{s}}(t)$ は，測定の時 間内では変化しないものとする，複素ヤング率の実部と虚部は次 のように定義される.

$$
\begin{aligned}
& E^{\prime}(\omega)=\left(\sigma_{0} / \varepsilon_{0}\right) \cos \delta \\
& E^{\prime \prime}(\omega)=\left(\sigma_{0} / \varepsilon_{0}\right) \sin \delta
\end{aligned}
$$

このとき発生する複屈折 $\Delta n$ は，伸長方向とそれと垂直な方向の 屈折率をそれぞれ $n_{1}, n_{2}$ として，

$$
\begin{aligned}
\Delta n(t) & \equiv n_{1}-n_{2} \\
& =\Delta n_{\mathrm{S}}+\Delta n_{\mathrm{D}} \\
& =\Delta n_{\mathrm{S}}+\Delta n_{0} \sin \left(\omega t+\delta_{\mathrm{B}}\right)
\end{aligned}
$$

と書ける。ここで， $\Delta n_{\mathrm{s}}$ と $\Delta n_{\mathrm{D}}$ はそれぞれ静的及び動的ひずみ によるものを表し， $\Delta n_{\mathrm{s}}$ は応力と同様に時間に依存しないとする. 複素ひずみ光学係数を, 複素ヤング率と同様に次式で定義する。

$$
\begin{aligned}
& O^{\prime}(\omega)=\left(\Delta n_{0} / \varepsilon_{0}\right) \cos \delta_{\mathrm{B}} \\
& O^{\prime \prime}(\varepsilon)=\left(\Delta n_{0} / \varepsilon_{0}\right) \sin \delta_{\mathrm{B}}
\end{aligned}
$$

光弾性則は, 次の二つの式で表される.

$$
\begin{aligned}
& O^{\prime}(\omega)=C E^{\prime}(\omega) \\
& O^{\prime \prime}(\omega)=C E^{\prime \prime}(\omega)
\end{aligned}
$$

ここで, 光弾性係数 $C$ は周波数に依存しない. 光弾性則は無定形 高分子の場合, 流動領域およびゴム状平坦領域の周波数範囲で成 立することが知られている ${ }^{13)}$.

試料の前後に, 偏光方向を直交させた偏光フィルムを拉いて透 過光を測定する場合, 試料の伸長方向と偏光方向の間の角度を $\pi / 4$ とすると, 透過光強度 $I$ は,

$$
I / I_{0}=\sin ^{2}(\Delta n d \pi / \lambda)
$$

となる．ここで， $d$ は膜の厚さ， $I_{0}$ は入射光強度を表す. $\Delta n$ を 式(6)で表し，式(11)に代入し， $\Delta n_{\mathrm{D}}$ が微小として $\Delta n_{\mathrm{s}}$ の近傍で展 開すると，

$$
\begin{aligned}
I / I_{0}= & \sin ^{2}\left(\Delta n_{\mathrm{s}} k+\Delta n_{\mathrm{D}} k\right) \\
= & \sin ^{2}\left(\Delta n_{\mathrm{s}} k\right)+\sin \left(2 \Delta n_{\mathrm{s}} k\right)\left(\Delta n_{\mathrm{D}} k\right) \\
& +\cos \left(2 \Delta n_{\mathrm{S}} k\right)\left(\Delta n_{\mathrm{D}} k\right)^{2}+\cdots \cdots \\
= & \sin ^{2}\left(\Delta n_{\mathrm{s}} k\right)+\sin \left(2 \Delta n_{\mathrm{s}} k\right)\left(\Delta n_{0} k\right) \sin \left(\omega t+\delta_{\mathrm{B}}\right) \\
& +\cos \left(2 \Delta n_{\mathrm{s}} k\right)\left(\Delta n_{0} k\right)^{2} \sin ^{2}\left(\omega t+\delta_{\mathrm{B}}\right)+\cdots \cdots
\end{aligned}
$$




$$
\begin{aligned}
= & \sin ^{2}\left(\Delta n_{\mathrm{s}} k\right)+1 / 2 \cos \left(2 \Delta n_{\mathrm{s}} k\right)\left(\Delta n_{0} k\right)^{2} \\
& +\sin \left(2 \Delta n_{\mathrm{s}} k\right)\left(\Delta n_{0} k\right) \sin \left(\omega t+\delta_{\mathrm{B}}\right) \\
& -1 / 2 \cos \left(2 \Delta n_{\mathrm{S}} k\right)\left(\Delta n_{0} k\right)^{2} \cos 2\left(\omega t+\delta_{\mathrm{B}}\right)+\cdots \cdots
\end{aligned}
$$

となる. ここで, $k=d \pi / \lambda$ と打いた. $\Delta n_{\mathrm{s}} k=m \pi,(m=0, \pm 1$, $\pm 2, \cdots \cdots)$ の場合には,

$$
I / I_{0}=1 / 2\left(\Delta n_{0} k\right)^{2}-1 / 2\left(\Delta n_{0} k\right)^{2} \cos 2\left(\omega t+\delta_{\mathrm{B}}\right)+\cdots \cdots
$$

となるから, 角振動数 $2 \omega$ の波の振幅と位相を求めれば, 複素ひ ずみ光学係数を求めることができる. $\Delta n_{\mathrm{s}} k=(2 m+1) \pi / 2$ の場合 にも, 角振動数 $2 \omega$ の波となるが, 直流成分が大きく, 余り実験 に適さないと思われる。

$\Delta n_{\mathrm{s}} k=(1 / 4+1 / 2 m) \pi$ の場合には，2 次の項が0となって,

$$
\begin{aligned}
I / I_{0} & =\sin ^{2}\left(\Delta n_{\mathrm{s}} k\right)+\sin \left(2 \Delta n_{\mathrm{S}} k\right)\left(\Delta n_{0} k\right) \sin \left(\omega t+\delta_{\mathrm{B}}\right)+\cdots \cdots \\
& =1 / 2 \pm\left(\Delta n_{0} k\right) \sin \left(\omega t+\delta_{\mathrm{B}}\right)+\cdots \cdots
\end{aligned}
$$

となり，角振動数 の波の振幅と位相を測定すれば良い。ここで， 式(14)の符号は， $m$ が偶数のとき正となる.

\section{4. 動的複屈折測定装置}

\section{$4 \cdot 1$ 装置の概成と測定法}

Fig. 1 亿動的複屈折測定装置のブロック図を示す. 基本的に は, 振動型レオメーター（レオロジー, DVE-3）に光学系を取 り付けたものである。このレオメーターは, 1〜 $1000 \mathrm{~Hz}$ の周波数 範囲で，最大 $100 \mu \mathrm{m}$ の振幅の変形を与えることができるが，装 置全体の共振のため, 複素ヤング率の測定は $1 \sim 200 \mathrm{~Hz}$ の範团に 限られる. 光学系は, He-Ne レーザー L, 偏光子 $\mathrm{P}$, 補償板 $\mathrm{C}$, 検光子 $\mathrm{A}$, 光検出器 $\mathrm{PD}$ からな. 図に示すように, 偏光子と検 光子の方向は直交し，またそれぞれ試料の伸長方向と $\pi / 4$ の角 度をなす。ホトダイオードの出力は, ロックインアンブ LA (Princeton Applied Research, 5210) に導入され, 角振動数 $\omega$ もしくは $2 \omega$ の波形について，その振幅とひずみに対する位相差 が求められる。この結果は, DVE-3 のコンピューターで処理さ れ, ひずみ光学係数が得られる仕組になっている.

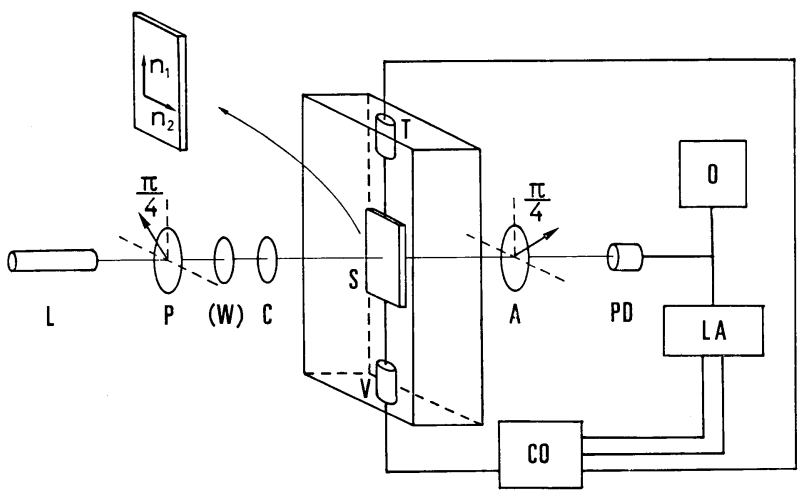

Fig. 1 Block diagram of the apparatus. S : sample, $\mathrm{T}$ : force transducer, $\mathrm{V}$ : vibrator, $\mathrm{L}$ : laser, $\mathrm{P}$ : polarizer, $\mathrm{A}$ : analyzer, $\mathrm{W}$ : quarter wave plate, C : compensator, $\mathrm{PD}$ : photodetector, LA : lock-in-amplifier, O : oscilloscope, $\mathrm{CO}$ : computer.
前節で見たように，測定方法は $\Delta n_{\mathrm{s}}$ の值によって変わってく る. $\Delta n_{\mathrm{s}}$ は，静的荷重（ひずみ）を変化させるか，補償板を利用 することによって変えることができる，補償板を適当に操作すれ ば, $\Delta n_{\mathrm{s}} k=m \pi$ に対応する条件を作ることができて，その場合に はホトダイオードからの信号は角振動数 $2 \omega$ の波形となり，これ はオシロスコープで容易に観測することがでさる. $\Delta n_{\mathrm{s}} k=(1 / 4+$ $1 / 2 m) \pi$ の条件は，Fig. 1 に示すよ 5 に $1 / 4$ 波長板Wを光学系に 加えれば容易に作れ，ホトダイオードからの信号は角振動数 $\omega$ の 波形となる。

\section{$4 \cdot 2$ 予備実験}

装置の検定のために，光弾性則が成り立つと考えられるゴム状 試料について測定を行った。試料はポリブタジェンの低度架橋フ イルム（厚さ $1 \mathrm{~mm}$ ) である.このポリブタジェンの光弾性係 数は, 複屈折と応力の緩和測定から $3.2 \times 10^{-10} \mathrm{~Pa}^{-1}$ であった. 動的複屈折の測定用試料の大きさは $5 \times 20 \mathrm{~mm}$ とし, 両端 $5 \mathrm{~mm}$ の部分をエポキシ樹脂で硬め，この部分をレオメーターのチャッ クで挾んで支持した.

$\Delta n_{\mathrm{s}} k=0$ の条件と, $\Delta n_{\mathrm{s}} k=1 / 4 \pi$ の条件について測定を行った. $\Delta n_{\mathrm{s}} k=0$ の条件では， $O^{\prime}$ と $O^{\prime \prime}$ の符号が求まらない欠点がある. $O^{\prime}$ と $O^{\prime \prime}$ のそれぞれの絶対值に関しては, $\Delta n_{\mathrm{s}} k=0$ と, $\Delta n_{\mathrm{s}} k=$ $1 / 4 \pi$ の結果は，実験䛊差内で一致した.

Fig. 2 に, 温度 $30^{\circ} \mathrm{C}$ に打けるポリブタジェンの複素ヤング率 とひずみ光学係数の周波数依存性を示す. $E^{\prime}$ の周波数依存性は 極めてわずかで，その值は約 $2 \times 10^{6} \mathrm{~Pa}$ である. $E^{\prime \prime}$ は $E^{\prime}$ の約 10\%であり，典型的なゴム状高分子の複素ヤング率であることが わかる. $O^{\prime}$ と $O^{\prime \prime}$ にも周波数依存性は注とんどなく， $O^{\prime \prime}$ は $O^{\prime}$ の 約 $10 \%$ ある。. 一見して， $O^{\prime}$ と $E^{\prime} ， O^{\prime \prime}$ と $E^{\prime \prime}$ の間に比例関係が 成立し，光弾性則が成り立つことがわかる。得られた光弾性係数 は， $3.1 \times 10^{-10} \mathrm{~Pa}^{-1}$ であり，この值は複屈折と応力の緩和測定 の結果と一致した.

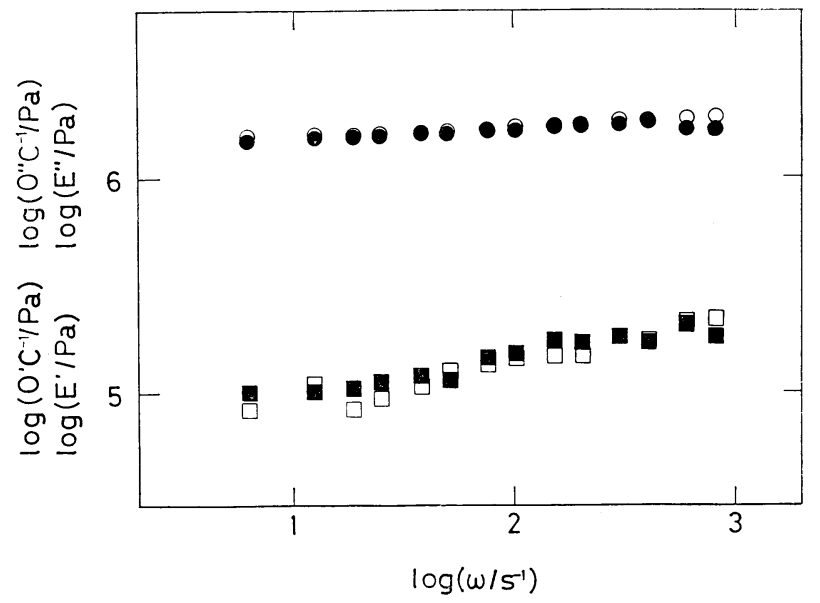

Fig. 2 Frequency dependence of complex strain-optical coefficient $\left(O^{\prime}, O^{\prime \prime}\right)$ and Young's modulus $\left(E^{\prime}\right.$, $\left.E^{\prime \prime}\right)$ of a polybutadiene.

: $E^{\prime}, \square: E^{\prime \prime}, \bigcirc: O^{\prime}, \square: O^{\prime \prime}$

\section{5. ポリスチレンに関する予備的結果}

無定形高分子の転移領域に搞ける動的複屈折の例として, ポリ スチレンの測定結果を示す。ガラス転移温度を下げるため，可塑 


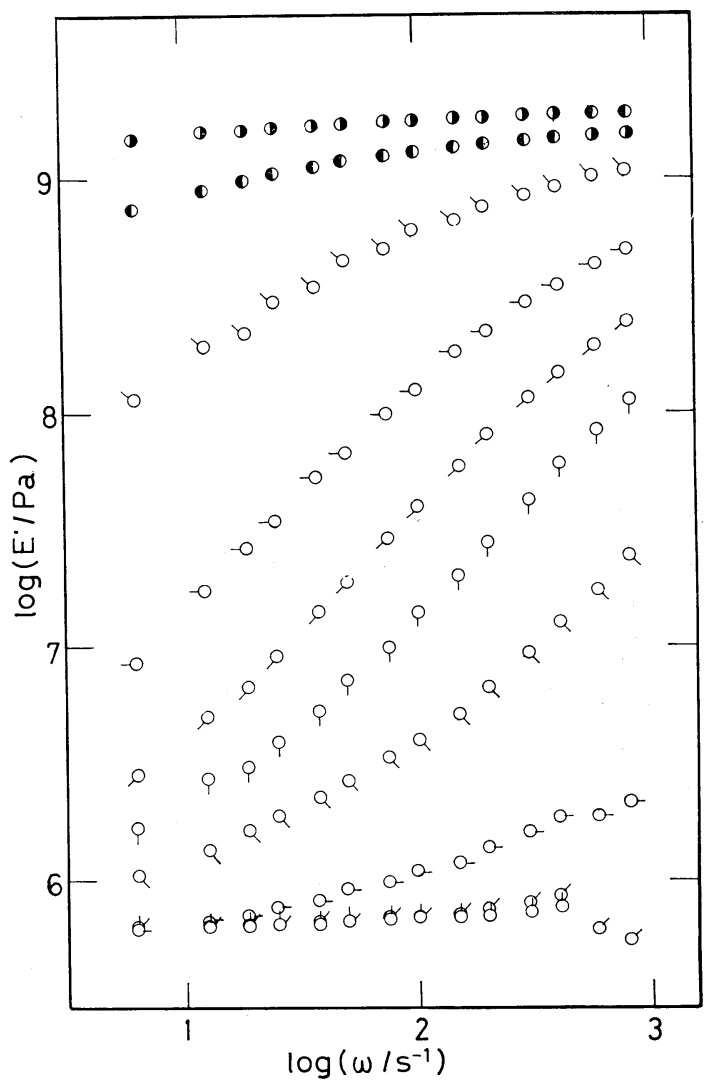

Fig. 3 Frequency dependence of $E^{\prime}$ of the PS-DBP 95/5 film. o : $180^{\circ} \mathrm{C}, \sigma: 160^{\circ} \mathrm{C}, \circ: 130^{\circ} \mathrm{C}, \quad \circ: 110$ ${ }^{\circ} \mathrm{C}, \quad \mathrm{P}: 105^{\circ} \mathrm{C}, \quad \mathrm{O}: 110^{\circ} \mathrm{C},-\circ: 95^{\circ} \mathrm{C}, \quad \mathrm{O}: 90^{\circ} \mathrm{C}$, (1) $80^{\circ} \mathrm{C}, \quad: 70^{\circ} \mathrm{C}$

剤としてフタル酸ジブチルを $5 \mathrm{wt} \%$ を加えてある．試料の調製 は，溶媒に塩化メチレンを用いて，溶媒蒸発法により行った。測 定温度範囲は 180 〜 $70^{\circ} \mathrm{C}$ である。まず，Fig. 3 亿複素ヤング率 $E^{\prime}$ の結果を示す. $180^{\circ} \mathrm{C} て ゙ は ， E^{\prime}$ の周波数依存性は小さく，その 值は約 $6 \times 10^{5} \mathrm{~Pa}$ であり，ゴム状平坦領域に相当していることが わかる．短冊状の試料を用いる本測定法では，原理的に流動領域 や，ゴム状領域の長時間側で測定を行うことは困難であるが，今 回の測定では高分子量の試料を用いたため, 測定領域をゴム状領 域の短時間側まで広げることが可能となった，温度の低下ととも

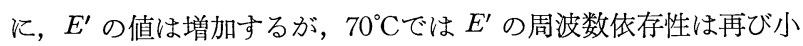
さくなる．この領域での $E^{\prime}$ の值が約 $2 \times 10^{9} \mathrm{~Pa}$ であることから， ガラス状領域であると考穴られる。

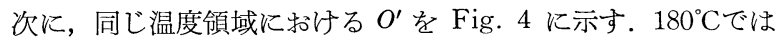
$O^{\prime}$ は平坦で，その值は約 $-3 \times 10^{-3}$ である. 温度が低下すると， $O^{\prime}$ の絶対值は最初は增加するが，さらに温度が低下すると，極 大を示した後, 減少しはじめる. $70^{\circ} \mathrm{C} て ゙ は ， O^{\prime}$ の符号は負から 正に変わる. 上記の $O^{\prime}$ の挙動は, Read の無定形高分子の動的複 屈折の結果と定性的に一致する.ポリスチレンはゴム状領域とガ ラス状領域で光弾性則が成立し, またその時の光弾性係数の符号 がそれぞれ負と正であると言われている．ゴム状平坦領域である $180^{\circ} \mathrm{C} て ゙ は ， O^{\prime}$ と $E^{\prime}$ の間に比例関係が成立した。 ここでは示さ

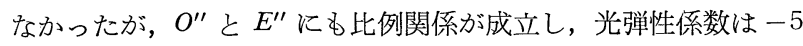
$\times 10^{9} \mathrm{~Pa}^{-1}$ と求まった。 この值は文献值と等しい，温度が低下す

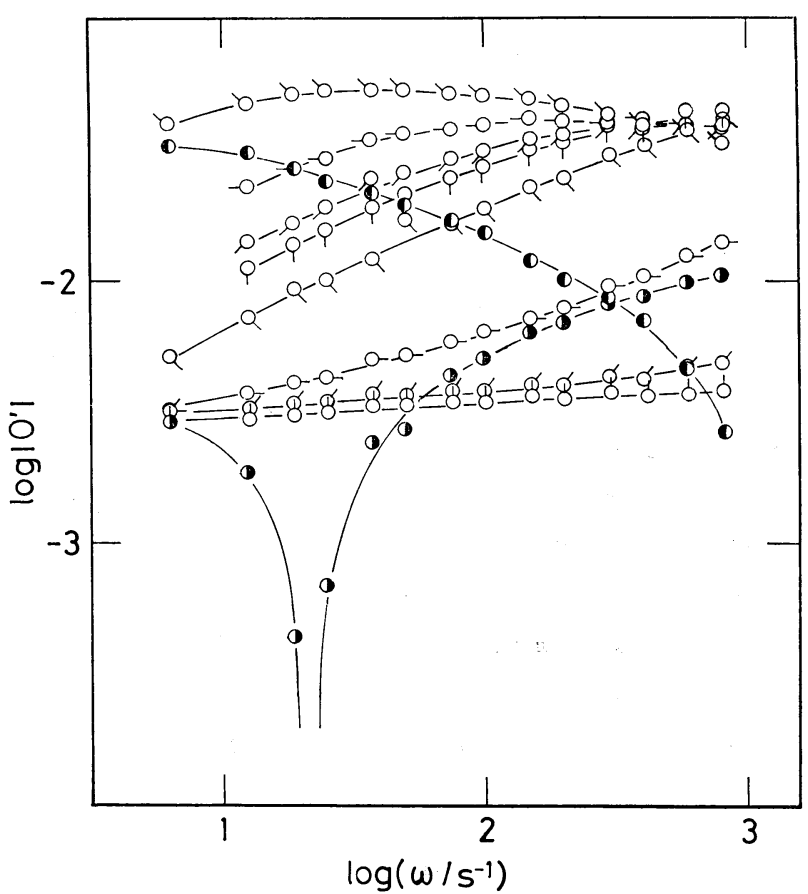

Fig. 4 Frequency dependence of $O^{\prime}$ of the PS-DBP 95/5 film. Symbols are the same as Fig. 3.

ると，光弾性則が成り立たないのは，Fig. 3, Fig. 4 から明らか である。 $O^{\prime}$ の符号の変化は, ゴム状領域とガラス状領域で光弾性 係数の符号が異なることに対応している，より低温では， $O^{\prime}$ と $E^{\prime}$ が共に平坦となって，光弾性則が成立するかもしれない，た だし, 複素量での光弾性則は, 式(9)と式(10)で表されるように, 実 部と虚部の両方で成立しなければならない，今後， $E^{\prime \prime}$ と $O^{\prime \prime}$ 含めた解析を行って, 無定形高分子のガラス転移領域について, 詳細な検討を行ってみたい。

以上のように，今回開発した測定装置を用いて，ゴム状領域か らガラス状領域までの幅広い領域にわたって，動的複屈折の測定 が精度良く行えることがわかった。

謝辞この研究は, 平成 2 年度文部省科学研究費補助金 （02453101）により行われた。

\section{参考文献}

1) Tsvetkov, V.N., in "Newer Methods of Polymer Characterization", Ke, B. ed., Wiley, NY, 1964, Ch. 14.

2）例总ば, Martel, C.J.T., T.P. Lodge, M.G. Dibbs, T.M. Stokich, R.L. Sammler, C.J. Carriere, and J.L. Schrag, Faraday Symp. Chem. Soc., 18, 4910 (1983) and References therein.

3) Stein, R.S., and A.V. Tobolsky, Textile Research J., 18, 201, 302 (1948).

4) Onogi, S., D.A. Keedy, and R.S. Stein, J. Polym. Sci., 50, S15 (1961).

5) Symposium on Rheo-optics of Polymers in J. Polym. Sci., Part C, No. 5 (1964).

6) Stein, R.S., in "Newer Methods of Polymer Characteri. 
zation", Ke, B. ed., Wiley, NY, 1964, Ch. 4.

7) Stein, R.S., "Rheology, Theory and Applicaitons", Academic Press, NY (1968), Vol. V, Ch. 6.

8) Samuels, R.J., "The Science and Technology of Polymer Films", O.J. Sweeting ed. Interscience, NY, 1968, Vol. 1, Chap. 7.

9) Onogi, S., and T. Asada, "Rheology, Vol. 1: Principles", G. Astarita, ed., Plenum Press, NY, 1980.

10) Read, B.E., Polym. Eng. Sci., 23, 835 (1983).

11) Janeschitz-Kriegl, H., Adv. Polymer Sci., 6, 170 (1969).

12) Wales, J.L.S., "The Application of Flow Birefringence to Rheological Studies of Polymer Melts." Delft Univ. Press, 1976.

13) See for example, Janeschitz-Kriegl, H., "Polymer Melt Rheology and Flow Birefringence" Springer-Verlag, Berlin, 1983.

14） Osaki，K.，日本レオロジー学会誌，9，139 (1981).

15) Osaki, K., E. Takatori, M. Ueda, M. Kurata, T. Kotaka, and H. Ohnuma, Macromolecules, 22, 2457 (1989).

16) Kornfield, J.A., G.G. Fuller, and D.S. Pearson, $M a$ cromolecules, 22, 1334 (1989).

17) Inoue, T., S. Shibasaki, and K. Osaki, to be published. 